\title{
Práticas restaurativas no ambiente escolar visando a desjudicialização de conflitos e enfrentamento da evasão escolar ${ }^{1}$
}

\section{Restorative practices in the school environment following the non judicial ways of conflicts and facing school dropout cases}

\author{
Gisele do Belem Andrekowicz* \\ Patricia Manente Melhem Rosas ${ }^{\star *}$
}

\begin{abstract}
Resumo: O objetivo da presente pesquisa foi verificar como a Justiça Restaurativa pode auxiliar na desjudicialização de conflitos escolares, bem como aferir a possibilidade de utilizar práticas restaurativas no enfrentamento da evasão escolar. A partir disso, conclui-se que a aplicação da Justiça Restaurativa dentro da escola pode ressignificar a realidade de adolescentes em conflito no ambiente escolar, gerando responsabilidades, dando voz aos verdadeiros interessados na resolução, evitando que seus conflitos sejam resolvidos por terceiros - que em alguns casos, sequer conhecem a realidade daquele ambiente -, e, permitindo o envolvimento de toda a comunidade escolar e familiar em casos que podem ser resolvidos sem a tomada de medidas judiciais, despertando no aluno o interesse em permanecer nesse ambiente escolar e evitando que seja acolhido pela criminalidade. Para o desenvolvimento do trabalho foi necessária a utilização da técnica de pesquisa bibliográfica, através dela realizadas análises e leituras de doutrinas e artigos sobre o tema abordado, assim como debates no Grupo de Estudos sobre Justiça Restaurativa no Centro Universitário Campo Real em Guarapuava/Paraná.

Palavras-chave: Justiça Restaurativa; resolução de conflitos; escola.
\end{abstract}

\footnotetext{
${ }^{1}$ Uma versão preliminar deste texto foi apresentada no "III SIMPÓSIO INTERNACIONAL INTERDISCIPLINAR EM CIÊNCIAS SOCIAIS APLICADAS: Democracia e direitos humanos" realizado em Ponta Grossa- PR, entre 11 a 13 de setembro de 2019, sendo indicado pelo evento para compor este volume especial da Emancipação.

* Bacharel em Direito pelo Centro Universitário Campo Real (2018). Pós-graduanda em Direito Penal e Processual Penal no Grupo Educacional Verbo Jurídico. Pós-graduanda em Direito Administrativo na Faculdade Única. Membro do grupo de estudos sobre Justiça Restaurativa no Centro Universitário Campo Real. E-mail: giseleandrekowicz@gmail.com.

** Doutora em Ciências Sociais Aplicadas pela Universidade Estadual de Ponta Grossa. Possui graduação em Direito pela Universidade Estadual de Ponta Grossa (2002) e mestrado em Direito pela Universidade Federal do Paraná (2008). Coordenadora de grupos de estudos sobre Justiça Restaurativa no Centro Universitário Campo Real. Pró-reitora Acadêmica do Centro Universitário Campo Real. Coordenadora da Pós-Graduação em Gestão de Conflitos do Centro Universitário Campo Real. Instrutora de facilitadores de processos circulares. E-mail: prof_patriciamelhem@camporeal.edu.br.
}

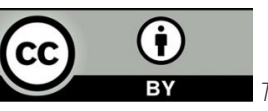




\begin{abstract}
The objective of the present research was to verify how Restorative Justice can help in school conflicts, as well as to verify the possibility of using restorative practices in face of school dropout. From this, it is concluded that the application of Restorative Justice within the school can reframe the reality of adolescents in conflict in school environment, generating responsibilities, giving voice to the real stakeholders in the resolution, avoiding that their conflicts are solved by third parties - that in some cases, do not even know the reality of that environment - and, allowing the involvement of the entire school and family community in cases that can be solved without judicial action, arousing in the student the interest in remaining in that school environment and preventing entry into crime. For the development of the work, it was necessary to use the bibliographical research technique, through which analyzes and readings of doctrines and articles on the subject addressed, as well discussion in the Group of Studies on Restorative Justice in Centro Universitário Campo Real in Guarapuava/Paraná.
\end{abstract}

Key-Words: Restorative Justice; conflict resolution; school.

Recebido em 18/09/2020. Aceito em 09/10/2020.

\title{
Introdução
}

A presente pesquisa objetiva perceber se a aplicação da Justiça Restaurativa nos casos em que há conflitos no ambiente escolar pode contribuir na desjudicialização dos conflitos e consequentemente na amenização da evasão escolar.

A escolha pelo tema decorre dos recentes estudos acerca da difusão da Justiça Restaurativa para alunos no ambiente escolar, bem como perceber se esse ambiente é propício para tais práticas, de modo que contribua na permanência e desperte o interesse desse adolescente em permanecer na escola em vez de optar pela continuidade e aperfeiçoamento delitivo.

Para o desenvolvimento da pesquisa, destaca-se a pesquisa bibliográfica, artigos publicados e debates oriundos do Grupo de Estudos sobre Justiça Restaurativa do Centro Universitário Campo Real em Guarapuava/Paraná.

\section{Desenvolvimento}

Os conflitos estão presentes em todas as esferas e organizações na sociedade, fazem parte dos ambientes e os modificam. Contudo, isso não significa que eles devam ser associados a doença social. As pessoas estão habituadas à cultura da guerra, conforme dispõe Penido (2016, p. 75), sob argumentos de que "a violência é inevitável, há algo de errado com o ser humano, sem castigo e punição não há respeito à ordem, existem pessoas boas e más, os maus merecem ser punidos", em discursos que são repetidos e geram a conclusão de que a justiça só é alcançada mediante retaliação. 
Para a abordagem de tal temática, faz-se necessário expor, inicialmente, que a presente pesquisa foi realizada a partir do procedimento bibliográfico. De acordo com Gil (2002, p. 44):

A pesquisa bibliográfica é desenvolvida com base em material já elaborado, constituído principalmente de livros e artigos científicos. Embora em quase todos os estudos seja exigido algum tipo de trabalho dessa natureza, há pesquisas desenvolvidas exclusivamente a partir de fontes bibliográficas. Boa parte dos estudos exploratórios pode ser definida como pesquisas bibliográficas. As pesquisas sobre ideologias, bem como aquelas que se propõem à análise das diversas posições acerca de um problema, também costumam ser desenvolvidas quase exclusivamente mediante fontes bibliográficas.

Sendo assim, uma das principais fontes do presente trabalho decorre de livros, produções científicas, leis, dentre outros, ou seja, de materiais já elaborados, tratados e disponíveis para acompanhamento e embasamento teórico.

\section{O conflito escolar trabalhado sob o viés da Cultura da Paz}

Não é raro perceber que algumas violências se tornam invisíveis em decorrência de um processo de omissões, aceitação de conflitos mal resolvidos ou até inclusão como parte da sociedade. De fato, os conflitos fazem parte do cotidiano e da vida em sociedade, o que não significa que necessariamente devem ser associados a doença social.

Visando romper esse ciclo vicioso de violências, a construção da Cultura da Paz relaciona-se àquilo que cuidamos e cultivamos em nós, em uma busca por atitudes e comportamentos de vida que rejeitam a comunicação violenta e visam à resolução de conflitos pelo diálogo e pela negociação, estimulando as formas de convivência que reconheçam a importância do conflito nos relacionamentos. Ainda, a Cultura de Paz não se limita a promover procedimentos pontuais para resolução de conflitos, mas sim pretende olhar para um todo, para que não consista apenas em uma prática isolada dentro do sistema (PENIDO, 2016, p. 73-74).

Nas palavras de Mumme (2016, p. 91):

[...] A Cultura de Paz tem duas missões: primeiro, tornar visíveis as violências que se perpetuam pela omissão ou pela aceitação de condições humilhantes como sendo próprias da nossa sociedade ou, pior ainda, intrínsecas à natureza humana. Segundo, estimular novas formas de convivência que abordem o conflito como instrumento necessário à manutenção democrática dos relacionamentos. Uma sociedade pautada na liberdade é plural, apenas os totalitarismos são singulares. Portanto, os conflitos não devem ser impedidos, mas trabalhados de modo edificante para que a divergência possa descobrir espaços de articulação e crescimento mútuo, reafirmando a convicção de que a paz é sempre possível, e a violência evitável.

Dentro do ambiente escolar, os conflitos podem decorrer de diversos motivos, dentre eles: discussões entre alunos, alunos e professores, entre funcionários ou com envolvimento de pais de alunos, que, se não resolvidos de forma adequada e trabalhados de forma positiva no próprio ambiente, podem resultar em violências perpetuadas e repetidas fora da escola, ocasionando um problema que pode envolver toda a sociedade. Esse ciclo de violências pode e deve ser rompido no cerne da questão, ou seja, dentro da própria escola. 
Para Penido (2016, p. 83), “a Justiça é um valor que diz respeito a todos e não se faz apenas no Fórum, sendo necessário criar espaços seguros e acolhedores para a sua materialização”, bem como a sua conscientização a partir do ambiente adequado e voltado à discussão e formação que a escola proporciona, como um método de trabalhar com o conflito onde ele iniciou.

No ambiente escolar, o conflito pode ser trabalhado e incentivado por seus funcionários. Cabe aos profissionais do ramo verificar o conflito e dar a ele sua importância, visando a Cultura de Paz. Ocorre que, conforme Branci, Manzini e Palmieri (apud SALLES, 2016, p. 8), "excluir o diferente ou o divergente para instaurar a paz entre os iguais não significa resolver os conflitos, mas ser intolerante ao conflito (...)", e tal resultado só é alcançado com a transformação dos conflitos e com a formação de professores, pedagogos, diretores, ou seja, os maiores envolvidos nessa redescoberta.

Quando se fala em trabalho do conflito visando um aprimoramento da Cultura da Paz, não se está afirmando e buscando a implementação de uma "sociedade utópica, "faz-de-conta" ou até mesmo, sem conflito algum, mas uma busca pela resolução de conflitos por meio da negociação. Em um ambiente escolar em que os conflitos são tidos como negativos, que levam relações ao limite, pressupondo violências, não há construção de paz.

Para se chegar na Educação para a Paz, urge mencionar e compreender os conflitos de maneira aprofundada, a partir do estudo na Conflitologia. Jares (apud SALLES, 2016, p. 2) conceitua Educação para a Paz como:

(...) um processo educativo, contínuo e permanente, fundamentado nos dois conceitos fundadores (concepção de paz positiva e perspectiva criativa do conflito), que, pela aplicação de métodos problematizantes, pretende desenvolver um novo tipo de cultura, a cultura de paz, que ajude as pessoas a entender criticamente a realidade social, desigual, violenta, complexa e conflituosa, para poder ter uma atitude e uma ação diante dela.

Dispor sobre conflitos no ambiente escolar não requer necessariamente associá-lo ao ódio ou a brigas, mas ao trabalho do conflito por meio da Cultura da Paz e de como ela pode redimensioná-lo, tanto na escola, quanto principalmente na sociedade. A construção da Cultura da Paz relaciona-se àquilo que as pessoas cultivam, em uma busca por atitudes e comportamentos de vida que rejeitam a comunicação violenta e visam a resolução de conflitos pelo diálogo e negociação, estimulando as formas de convivência que reconheçam a importância do conflito nos relacionamentos (PENIDO, 2016, p. 73-74).

Portanto, uma das maneiras de se trabalhar o conflito de uma forma mais humanizada e buscando a efetivação da Cultura da Paz pode ser obtido a partir das práticas restaurativas, conforme será aduzido em seguida.

\section{Justiça Restaurativa}

O termo "Justiça Restaurativa” advém de relações e de sentimento de justiça entre os participantes. É um processo cuja participação dos envolvidos é voluntária e é realizado em locais em que a infraestrutura remete a algo confortável, sem o aspecto jurídico que uma sala de audiência representa, utilizando-se de técnicas em busca de um resultado restaurativo (PINTO, 2005, p. 20).

Um dos conceitos mais difundidos de Justiça Restaurativa, em que há preocupação nas relações futuras, foi desenvolvido por Marshal e Roche, que é considerado como um processo que 
une os grupos afetados em um incidente ofensivo, pois, ao passo que se unem, decidem como lidar com suas consequências e implicações para o futuro de forma coletiva (BRANCHER, 2013, p. 98).

De acordo com Zehr:

Justiça Restaurativa é uma abordagem que visa promover justiça e que envolve, tanto quanto possível, todos aqueles que têm interesse numa ofensa ou dano específico, num processo que coletivamente identifica e trata os danos, necessidades e obrigações decorrentes da ofensa, a fim de restabelecer as pessoas e endireitar as coisas na medida do possível. (ZEHR, 2015, p. 54)

Nesse sentido, vale destacar que a Justiça Restaurativa abre uma relação horizontal e pluralista do que pode ser considerado justo pelos envolvidos em uma situação-problema, focando em suas necessidades e papéis, contrariando uma posição tradicional vertical entre indivíduo e sociedade (MELO, 2005, p. 60). Também, verifica-se que o movimento restaurativo segue parâmetros, parafraseando Nils Christie, dos "conflitos como propriedade", redistribuindo o poder e reduzindo as intervenções estatais, devolvendo às partes o direito de resolver suas desavenças (FROESTAD; SHEARING, 2005, p. 90).

As soluções alternativas ao sistema tradicional, encontram nas práticas restaurativas o atendimento das necessidades das vítimas, dando-lhes voz nos conflitos e a responsabilização do causador do dano utilizando-se de recursos menos punitivos e estigmatizantes, dando a essas partes mais afetadas pela infração outras possibilidades de enfrentamento e superação (MELO, 2005, p. 53).

Ademais, Morris (2005, p. 441) pontua que a Justiça Restaurativa enfatiza os Direitos Humanos e a necessidade de reconhecer o impacto de injustiças sociais e de alguma forma resolver esses problemas - ao invés de simplesmente oferecer aos infratores uma justiça formal ou positivada e às vítimas, justiça alguma. Nesse ponto, destaca-se a busca por uma "justiça" capaz de atender aos interesses de todas as partes em um processo, não apenas beneficiando ou, melhor dizendo, focando em uma parte em detrimento das outras.

Vale atentar que, quando se menciona acerca da justiça à vítima, ela não se confunde à prática usual de "fazer justiça com as próprias mãos", tendo em vista que deve-se considerar que o processo restaurativo, muito embora contenha traços de informalidade, reaviva e atualiza práticas comunitárias utilizadas ao longo do tempo (resolução de conflitos na comunidade, por exemplo), mas que foram perdidas e colocadas em desuso em razão do crescente número das comunidades ou em consequência de uma geração mais individualizada (PINTO, 2005, p. 28).

O ponto central da Justiça Restaurativa envolve retificar as coisas, oportunizando àqueles que causaram danos o estímulo a fazer a coisa certa, ante o que praticaram, implicando em uma responsabilidade, pois as decisões-chave são postas nas mãos dos mais afetados pelo crime/ ato infracional para a redução da probabilidade de ofensas futuras (ZEHR, 2015, p. 45). A Justiça Restaurativa permite que as decisões sejam tomadas pelos interessados no processo e que foram afetados pelo crime ou ato infracional, incluindo a vítima, o ofensor, a família e a comunidade, dando prioridade ao que lhes é benéfico. Dessa forma, o Estado perde o monopólio sobre o processo decisório - importante ressaltar, pois o Estado continua participando por intermédio de seus representantes, porém, não como principal tomador de decisões - seu papel é redefinido, tendo em vista que o crime não significará, exclusivamente, uma violação de seus interesses, mas como referido, violação dos interesses das partes (MORRIS, 2002, p. 3). 
Paul Maccold e Ted Wachtel (apud PINTO, 2005, p. 22) propõem três perguntas que norteiam a Justiça Restaurativa: "quem foi prejudicado?", "Quais as suas necessidades?" e "Como atender a essas necessidades?". Ainda, dispõe que a justiça convencional diz: "você fez isso e precisa ser castigado de acordo com o tipo penal!”, já a JR pergunta: “o que você pode fazer agora para restaurar isso?".

A Justiça Restaurativa pode ser concretizada a partir das chamadas práticas restaurativas. Não há modelo "mais correto", pois eles podem ser adaptados ao caso concreto, assim como nenhum modelo sobrepõe o outro em uma escala de efetividade. Vislumbra-se nos modelos restaurativos o favorecimento ao diálogo, oportunizando a tomada de decisões coletivas por meio das práticas restaurativas, ao readaptar o modelo litigioso que utiliza das conciliações e as audiências na resolução de conflitos.

Um dos modos que a Justiça Restaurativa utiliza para externar seus valores e pô-los em prática é a partir dos Círculos Restaurativos, que criam uma possibilidade de liberdade para expressar a verdade pessoal, sem máscaras e defesas, presente um ser humano inteiro, que tentará reconhecer seus erros para agir conforme preceitos fundamentais (PRANIS, 2010, p. 25). As práticas restaurativas permitem a sua efetivação tanto em ambientes judiciais, nas fases pré-processuais, execuções, e no caso de adolescentes, no ambiente escolar, tanto antes da judicialização dos conflitos, como no cumprimento de medidas socioeducativas, quando há apoio do judiciário.

Muito embora a Justiça Restaurativa tenha sua aplicação relativamente nova em comparação à justiça convencional, documentos oficiais, dentre eles os emitidos pela ONU e pela União Europeia, validam a Justiça Restaurativa no território internacional, como os princípios abarcados na Resolução do Conselho Econômico e Social das Nações Unidas, de 13 de agosto de 2012 (PINTO, 2005, p. 23):

1. Programa Restaurativo - se entende qualquer programa que utilize processos restaurativos voltados para resultados restaurativos.

2. Processo Restaurativo - significa que a vítima e o infrator, e, quando apropriado, outras pessoas ou membros da comunidade afetados pelo crime, participam coletiva e ativamente na resolução dos problemas causados pelo crime, geralmente com a ajuda de um facilitador. O processo restaurativo abrange mediação, conciliação, audiências e círculos de sentença.

3. Resultado Restaurativo - significa um acordo alcançado devido a um processo restaurativo, incluindo responsabilidades e programas, tais como reparação, restituição, prestação de serviços comunitários, objetivando suprir as necessidades individuais e coletivas das partes e logrando a reintegração da vítima e do infrator.

Mister ressaltar o posicionamento de Froestad; Shearing (2005, p. 91), de que os princípios que regem as práticas restaurativas são pautadas sob a premissa da construção da Cultura de Paz, visando a indicação de casos para além do "sistema de justiça criminal", a responsabilidade de seus participantes, a utilização de recursos e controles transpassados do patrocínio estatal para comunidades e leigos, bem como, garantir que as regras, procedimentos e mecanismos sigam os valores centrais da JR.

Os princípios que norteiam a Justiça Restaurativa podem ser divididos em:

(i) empoderamento do ofensor por meio do desenvolvimento de sua capacidade de assumir responsabilidade sobre seus atos e de fazer suas escolhas; 
(ii) reparo de danos, ou seja, contrariamente à Justiça estritamente retributiva, que se atém exclusivamente ao ofensor, a Justiça Restaurativa enfoca também a vítima, seu grupo familiar e suas necessidades a serem reequilibradas;

(iii) e, por fim, resultados integrativos, restaurando a harmonia entre os indivíduos, reestabelecendo o equilíbrio e identificando e provendo, por meio de soluções duradouras, necessidades não atendidas (CARVALHO, 2005, p. 218).

Ademais, de acordo com o art. 2º da Resolução nº 2002/2016, os princípios que orientam a Justiça Restaurativa são: corresponsabilidade, a reparação dos danos, o atendimento às necessidades de todos os envolvidos, informalidade, voluntariedade, imparcialidade, participação, empoderamento, consensualidade, confidencialidade, celeridade e urbanidade. A Justiça Restaurativa permite que as decisões sejam tomadas pelos interessados no processo e que foram afetados por ele, a partir do crime e/ou ato infracional, dando prioridade ao que lhes é benéfico. Dessa forma, o Estado perde o monopólio sobre o processo decisório - importante ressaltar, pois o Estado continua participando através de seus representantes, porém, não como principal tomador de decisões - seu papel é redefinido, tendo em vista que o crime não significará, exclusivamente, uma violação de seus interesses, mas como referido, violação dos interesses das partes (MORRIS, 2002, p. 3).

Os principais interessados em um processo são os que foram diretamente prejudicados e os que causaram o dano. Ademais, nesse círculo de interessados primários pode ser elencada a comunidade, através de seus membros que possuam vínculos com o que trata o caso. A Justiça Restaurativa permite, ainda, um círculo de interessados secundários, ou seja, familiares e amigos da vítima e ofensor (ZEHR, 2015, p. 43).

Zehr (2012, p. 32) refere-se ao crime como uma quebra de relacionamentos, uma chaga na comunidade pois seus vínculos são desfeitos, gerando, por conseguinte, causas e efeitos do crime. 0 crime em uma comunidade gera o mal, pois afeta a teia de relacionamentos. Essa teia de relacionamentos impõe ser necessárias obrigações e responsabilidades, não só do ofensor como se vê comumente, mas também da comunidade, pois quando essa teia se rompe, todos são afetados, inclusive os membros dessa comunidade.

Os valores restaurativos e valores retributivos podem ser contrapostos em alguns aspectos. No que tange o conceito de crime, a Justiça Retributiva parte de um conceito jurídico-normativo em que o crime é um ato contra o Estado, enquanto que na Justiça Restaurativa parte-se de um conceito realístico de crime, porquanto traumatize e cause danos à vítima, em uma espécie de multidisciplinariedade; na Justiça Retributiva os interesses são voltados a um monopólio estatal, em que o interesse público é superior ao privado, contrariando aos pressupostos restaurativos em que há uma justiça participativa; a culpabilidade na Justiça Retributiva é associada à estigmatização pois é voltada ao passado, à medida que a Justiça Restaurativa pauta-se na restauração compartilhada e voltada ao futuro, em uma cultura mais flexível a partir da Justiça Social e alternativa (PINTO, 2005, p. 24).

Os valores da Justiça Restaurativa são voltados à restauração de prejuízos, na qual os indivíduos assumem responsabilidades por suas ações visando o futuro. São considerados valores: (i) o encontro, para que vítima e ofensor possam compartilhar suas visões sobre o ocorrido e através da empatia encontrem uma maneira de repará-lo, de forma direta ou indireta; (ii) a inclusão, em que as partes têm voz para chegar às conclusões; (iii) a reparação, que não será necessariamente material ou pecuniária; (iv) a reintegração, por sua vez, permite que os participantes retornem à sociedade como membros contribuintes (PARKER, 2005, p. 248). 
Ademais, os processos passam por um grau de "restauratividade" calculados na medida em que expressam seus valores, também considerados como: participação, respeito, honestidade, humildade, cuidados mútuos, responsabilidade, empoderamento e verdade. Dispõe Marshall, Boyack e Bowen (2005, p. 267):

Deve-se enfatizar que processo e valores são inseparáveis na justiça restaurativa. Pois são os valores que determinam o processo, e o processo é o que torna visíveis os valores. Se a justiça restaurativa privilegia os valores de respeito e honestidade, por exemplo, é de crucial importância que as práticas adotadas num encontro restaurativo exibam respeito por todas as partes e propiciem amplas oportunidades para todos os presentes falarem suas verdades livremente. Por outro lado, conquanto estes valores sejam honrados, há espaço para vários processos e uma flexibilidade de práticas.

De maneira especificada, os valores divergem a Justiça Restaurativa de outras práticas. A participação diz respeito à tomada de decisões pelos mais afetados com o crime; o respeito trata das relações humanas independentemente das ações, pois todos devem ter resguardada sua dignidade nos ambientes em que estiverem acontecendo práticas restaurativas; no que tange a honestidade, dar oportunidade para que as pessoas falem sem a pressão da elucidação de fatos ou culpabilizando os participantes, pois permite que seja despertada a empatia, seus sentimentos em relação ao ocorrido e responsabilização moral; a humildade possibilita que os indivíduos reconheçam uns aos outros como seres humanos, sem se apegar ao conceito de inimigos que a vítima e ofensor podem transparecer, o que não significa que ambos saiam de uma prática restaurativa se abraçando e vivendo como se nada tivesse acontecido, mas que percebam o que possa ser melhorado para ambos daquele momento em diante, a partir do despertar da responsabilidade compartilhada, que é relacionada aos valores inerentes aos cuidados mútuos e responsabilidade; sobre o empoderamento, o ato infracional retira das pessoas o controle sobre sua autonomia, pois outra pessoa a exerceu sem o seu consentimento. Nesse sentido, a Justiça Restaurativa dá a elas papel ativo para que exponham suas necessidades (MARSHALL, BOYACK e BOWEN, 2005, p. 271-273).

Esse grau de restauratividade conferido a certas práticas é auferido com base nos valores restaurativos, tendo em vista que estes atuam como um filtro do que pode ser considerado restaurativo e ao que se compara a outros modos de soluções de conflitos diversos da Justiça Restaurativa.

Destarte, quando se fala que as práticas restaurativas devem ser seguir princípios e valores, busca-se de certo modo uma padronização, pois, mesmo que cada crime, ofensor, vítimas e comunidade tenham suas particularidades, a quebra de vínculos pode gerar efeitos sociais semelhantes, ou seja, os envolvidos devem partir dos mesmos pressupostos, mesmo que seus resultados sejam particulares a cada caso.

Como não há modelo "mais correto", pois eles podem ser adaptados ao caso concreto, e nenhum modelo sobrepõe o outro em uma escala de efetividade, conforme já citamos, os modelos habitualmente podem ser mesclados, ou seja, as conferências familiares podem utilizar-se de círculos e criam novas formas a partir da combinação de elementos de cada modelo e as diferenças entre eles diminuem. Contudo, todos os modelos possuem elementos importantes em comum, pois resultam de um encontro facilitado ou diálogo entre interessados, que podem ser diretamente a vítima e ofensor, seus substitutos ou em uma preparação para o encontro a partir de cartas ou vídeos (ZEHR, 2015, p. 62). 
Muito embora os modelos sejam semelhantes, eles se diferenciam pelo número de participantes e suas características, bem como ao tipo de facilitação, focando sempre nas necessidades e nos papéis dos envolvidos. Convém ressaltar que nem sempre ocorre um encontro direto ou que apenas um encontro irá resolver e atender a todas as necessidades, bem como dependerá da participação dos envolvidos voluntariamente e quando há o mínimo de intenção de quem praticou o dano em se responsabiliza

Em que pese a Justiça Restaurativa não possuir legislação específica até o presente momento, pois verifica-se que seu Projeto de Lei (nº 7006/2006) foi apensado ao projeto do Novo Código de Processo Penal ( $n^{\circ}$ 8045/2010), seus praticantes utilizam-se de legislações análogas, princípios gerais do direito, resoluções e, no caso de adolescentes, da Lei no 12.594/2012 (SINASE) - que prevê a possibilidade e preferência de práticas restaurativas.

Além do mais, como se verá adiante, a aplicação da Justiça Restaurativa não depende exclusivamente de legislação, haja visto que sua aplicação pode ser visualizada a partir de princípios e partindo do pressuposto da desjudicialização dos conflitos, como é o caso do ambiente escolar, em que o conflito sequer vai para a área judicial.

\section{A Justiça Restaurativa na resolução de conflitos escolares}

Atualmente, o Estatuto da Criança e do Adolescente (Lei no 8.069/90) enseja a aplicação de Justiça Restaurativa de forma indireta quando trata da aplicação da remissão (ECA, art. 126) e aplicação de medidas socioeducativas sobre o viés da doutrina da proteção integral do adolescente (ECA, art. 112 e seguintes) (PINTO, 2005, p. 32).

O ECA considera criança a pessoa de até doze anos incompletos e adolescente a pessoa entre doze e dezoito anos de idade. Se um indivíduo maior de dezoito anos pratica um crime ou contravenção penal, ao final do processo poderá ser aplicada uma pena pelo juiz, por isso se considera que os adultos são imputáveis, ou seja, pode ser imputado um crime/pena a ele previsto em lei. No caso de uma criança ou adolescente, quando há cometimento de conduta tipificada como crime ou contravenção penal, diz-se que ele praticou um ato infracional. Nesse sentido, são considerados inimputáveis, pois não se imputam crimes ou penas, mas sim, medidas socioeducativas e medidas protetivas previstas no ECA (NUNES, 2014, p. 83).

As medidas protetivas e medidas socioeducativas possuem caráter pedagógico em razão da situação de desenvolvimento, o que não significa impunidade, pois, por vezes, acaba sendo mais rigoroso que o punitivo. Para as crianças que cometem ato infracional, aplica-se o art. 101 do ECA, em razão da situação de risco e vulnerabilidade:

Art. 101. Verificada qualquer das hipóteses previstas no art. 98, a autoridade competente poderá determinar, dentre outras, as seguintes medidas:

I-encaminhamento aos pais ou responsável, mediante termo de responsabilidade;

II - orientação, apoio e acompanhamento temporários;

III - matrícula e frequência obrigatórias em estabelecimento oficial de ensino fundamental;

IV - inclusão em programa comunitário ou oficial de auxílio à família, à criança e ao adolescente;

V - inclusão em serviços e programas oficiais ou comunitários de proteção, apoio e promoção da família, da criança e do adolescente; 
VI- requisição de tratamento médico, psicológico ou psiquiátrico, em regime hospitalar ou ambulatorial;

VII - inclusão em programa oficial ou comunitário de auxílio, orientação e tratamento a alcoólatras e toxicômanos;

VIII - abrigo em entidade;

IX - acolhimento institucional;

X - colocação em família substituta;

XI inclusão em programa de acolhimento familiar;

XII - colocação em família substituta.

No caso do adolescente, estará sujeito a uma das medidas socioeducativas previstas no art. 112 do ECA e levam em consideração as circunstâncias e gravidade do ato infracional. São medidas socioeducativas: advertência, obrigação de reparar o dano, prestação de serviços à comunidade, liberdade assistida, inserção em regime de semi-liberdade, internação em estabelecimento educacional ou qualquer uma das medidas protetivas previstas no art. 101, I a VI do ECA (NUNES, 2014, p. 84).

As práticas restaurativas não se encontram previstas expressamente no Estatuto da Criança e do Adolescente como medidas socioeducativas. Para sua aplicação em adolescentes que cometeram ato infracional, vislumbra-se, por hora, que ela pode ser encaixada como uma medida protetiva, atendendo ao art. 112, inc. VII do ECA.

A educação na escola promove a autonomia, o saber, descoberta de aptidões, habilidades, capacidade de discernimento e ação, tendo em vista que, conforme mencionado, acaba sendo um dos primeiros ambientes sociais em que os indivíduos são inseridos, considerada uma das mais importantes instituições que contribuem para o desenvolvimento humano com base na integração social. Nesse sentido, a autonomia promovida por meio da educação é adquirida e reforçada com as experiências vividas e compartilhadas no local onde ela ocorre.

Partindo-se desse pressuposto, a escola acaba sendo um ambiente propício às práticas restaurativas, em decorrência do fim social semelhante a que se destinam, sendo esta última voltada ao restabelecimento de relações que foram rompidas, despertando o pertencimento a um grupo, respeito, compreensão e senso de responsabilidade (MELO apud SANTOS; GOMIDE, 2014, p. 43). Ademais, não há como deixar de associar escola e Justiça Restaurativa na busca do diálogo e paz, ou seja, quando se menciona "a cultura da não violência", logo se remete a posicionamentos em respeito à vida, à cultura do diálogo, à solução pacífica dos conflitos, ao respeito aos Direitos Humanos e à Dignidade da Pessoa Humana, posicionamentos que podem ser discutidos no ambiente escolar a partir da Justiça Restaurativa, por meio da abordagem colaborativa que resgata voz e conexão entre seus participantes (NUNES, 2014, p. 12).

Contudo, às vezes a escola acaba trabalhando de forma individualizada e limitando-se a repassar o aprendizado, deixando de lado o seu papel social ou não sabendo como lidar com os conflitos (SANTOS; GOMIDE, 2014, p. 43), sendo que nesse ambiente ocorrem as mais diversas espécies de conflito, sobretudo de relacionamentos, que acabam tomando rumos negativos que geram violências para além das salas de aula, se não trabalhados de forma adequada em decorrência de diversos fatores que podem estar relacionados à capacitação de profissionais, ambiente físico e aderência geral.

Para tanto, a Justiça Restaurativa promove meios de gerenciamento positivo de conflitos, em razão das discussões sobre sentimentos e necessidades não atendidos, restaurando relações 
rompidas. Em geral, as iniciativas por parte da escola para implementação de práticas restaurativas são voltadas a: promover a capacitação de facilitadores e formar equipes, que podem ser compostas por professores, funcionários da escola, pessoas da comunidade, alunos e/ou pais; separar um local pequeno, simples, porém aconchegante para realização das práticas; ter um local para solicitação das reuniões, o qual será acessado por alunos que desejem participar de uma prática restaurativa, bem como nesse mesmo local, pode ser encaminhado aquele aluno que cometeu ato indisciplinar para que seja oferecida uma reunião restaurativa; informar aos pais/responsáveis a adoção de alternativas de resolução de conflitos, solicitando autorizações e incentivando sua participação (NUNES, 2014, p. 55).

Os casos a serem encaminhados para as práticas restaurativas no ambiente escolar podem envolver diversos motivos, mas que significam e reconduzem seus alunos a soluções que podem evitar prejuízos futuros. Nunes (2014, p. 55) traz um caso ocorrido em uma escola estadual localizada em Assis-SP e narrado por uma professora que realizou um círculo restaurativo:

Na minha escola uma menina tímida estava sendo vítima de bullying porque usava a mesma meia todos os dias. Estava sendo ridicularizada e os colegas a chamavam de "pé-de-meia". Iniciei um pré círculo, ouvindo a menina e os ofensores e combinamos um círculo restaurativo. No dia do círculo, todos ficaram juntos: a vítima e os ofensores. A primeira a expor seus sentimentos foi a vítima. Ao ouvi-la, os ofensores ficaram tímidos e colocaram-se no lugar da jovem. Comprometeram-se a parar de importuná-la e protege-la caso alguém iniciasse tais constrangimentos. Depois de quinze dias, realizou-se o pós círculo e a aluna parecia estar com uma aparência mais segura e agradeceu emocionalmente a mim e aos alunos. Ela se sentia mais feliz e mais incluída no ambiente escolar.

Como se pode notar, o caso acima denota que um Círculo Restaurativo preveniu uma possível reação mais violenta por parte de uma vítima de bullyng e que permaneceu no âmbito escolar. A Justiça Restaurativa aliada à Construção da Paz pode ser usada de forma preventiva, no âmbito escolar, como forma de desjudicialização de conflitos, tal como ocorreu no caso colacionado acima. Ademais, a sua forma de atuação pode ser voltada a prevenir que aquele aluno que está inserido na escola e já teve contato com o sistema tradicional seja rotulado ou minimizar seus efeitos, tendo em vista que a Justiça Restaurativa permite o empoderamento daquele adolescente a partir do momento que o inclui na solução e não impõe apenas uma repressão (MELHEM; ROSAS, 2015, p. 8).

No caso em seguida, Brancher (2013, p. 40) relata um caso que evoluiu para além das salas de aula, envolvendo o Judiciário e provocando, inclusive, desavenças entre as famílias, vejamos:

As duas adolescentes de 14 anos eram colegas do oitavo ano do ensino fundamental quando brigaram na saída do colégio, resultando em uma delas com lesões corporais. Somente um ano depois, o caso entrou em pauta na Vara da Infância e da Juventude. Mesmo passado tanto tempo, o conflito não perdera sua atualidade. Pior, evoluíra para uma desavença entre as famílias. Novos boletins de ocorrência foram registrados, desta vez por ameaças. O caso foi encaminhado para um procedimento restaurativo. Com a participação das duas famílias, o encontro em forma de Círculo de Construção de Paz mostrou que o conflito entre as meninas vinha de longa data. Desde o quinto ano do Ensino Fundamental elas discutiam frequentemente. Uma delas viera de outra cidade, tinha hábitos interioranos e seu modo de vestir era motivo de chacota. A colega a chamava de 
"pano de chão", e ela revidava chamando-a de "patricinha". Já haviam sido chamadas muitas vezes para as tradicionais reuniões de aconselhamento, inclusive envolvendo familiares, mas o conflito não se resolvia. As desavenças evoluíram para as agressões relatadas. Uma das meninas trocou de escola depois do fato. Mas havia outras crianças das mesmas famílias que permaneciam no colégio, e o conflito se desdobrava entre elas. E foi além da escola, tensionando a vida das famílias na comunidade. Embora vizinhos, evitavam frequentar os mesmos lugares. Encontros ocasionais entre familiares, adultos, crianças e adolescentes faziam aflorar a hostilidade, com ameaças e até a iminência de agressões. 0 Círculo permitiu não somente às garotas, mas também aos familiares, desabafarem o mal-estar gerado pela rivalidade. As meninas reconheceram terem sentimentos em comum. Embora constassem no processo como ofensora e vítima, ambas admitiram ter praticado agressões. Frente a frente com a realidade e lado a lado com suas famílias, as duas perceberam a dimensão das consequências de seus atos. Sentiram-se responsáveis e arrependidas pela grande confusão em que tinham envolvido os familiares. Decidiram então pedir desculpas recíprocas, e aos seus familiares, e dar um fim às provocações. O processo foi arquivado, e as famílias voltaram a conviver pacificamente.

Um dos desafios para implantação de práticas restaurativas na escola envolve a aceitação e participação de seus próprios funcionários. O ciclo vicioso de reclamações dos professores em relação ao comportamento dos alunos associado à inadequação de condutas dos profissionais não promovem a auto responsabilização, devido ao jogo de empurra que é instalado: em que professores conferem a responsabilidade do comportamento moral ao setor pedagógico e/ou direção, e estes remetem a atribuição como sendo exclusiva dos pais - o que não é de todo modo errado, tendo em vista que alguns pais sequer comparecem às reuniões escolares para conferência de assuntos relacionados aos filhos (SANTOS; GOMIDE, 2014, p. 49).

Para evitar esse jogo de transferências de responsabilidades e efetivar as práticas restaurativas, a escola deve obter uma boa gestão democrática de modo a formar um conjunto interconectado formando uma estrutura de organização para efetivação das crianças e adolescentes que frequentam a escola, para que esses alunos se mantenham no ambiente escolar e isso não contribua para o fenômeno da evasão escolar.

\section{Evasão escolar de adolescentes: um problema social trabalhado nas perspectivas restaurativas}

As explicações para o fenômeno da evasão escolar são elucidadas por pesquisas voltadas a motivos internos da escola - que envolvem a figura do professor e método de aprendizagem - e motivos externos à escola - geralmente relacionados às drogas, a amizades, ao trabalho, à gravidez precoce, a desigualdades sociais e a relacionamentos familiares. Portanto, por envolver várias questões, tanto familiares quanto próprias da escola, a obrigação ao combate à evasão escolar não é de somente uma instituição. Conforme o art. 4º da Lei 8.069/90:

É dever da família, da comunidade, da sociedade em geral e do poder público assegurar, com absoluta prioridade, a efetivação dos direitos referentes à vida, à saúde, à alimentação, à educação, ao esporte, ao lazer, à profissionalização, à cultura, à dignidade, ao respeito, à liberdade e à convivência familiar e comunitária (grifo nosso). 
Dias (2013, p.73) pontua acerca da educação como um direito que não se limita à matrícula do aluno na rede de ensino, pois a amplitude legal defende o reconhecimento de uma educação gratuita e de qualidade, oferecendo condições ao aluno de permanecer na escola. Entretanto, a Doutrina da Proteção Integral contida no Estatuto da Criança e do Adolescente (Lei 8.069/90) nem sempre é respeitada, no sentido de que nem sempre o garantido na lei é efetivado nas escolas, constatando-se a ausência de ações políticas para garantir o acesso e permanência na escola, principalmente de adolescentes que tenham cometido ato infracional.

Costa Lima (apud DIAS, 2013, p. 74) menciona que a exclusão do ambiente escolar propicia ao adolescente que comete atos infracionais a limitação quanto à construção de novas significações sociais e consciência sobre sua situação, já que a condição de sujeitos de direitos está ligada à educação, ao passo que não se pode exercer a cidadania sem conhecimento dos códigos de modernidade que determinam os padrões sociais e educacionais.

O Sistema de Garantia de Direitos da Criança e do Adolescente (SGDCA), promove a articulação e integração de instâncias públicas governamentais e sociedade civil; promoção e aplicação de instrumentos normativos; e, funcionamento dos mecanismos que defendem e efetivam os direitos humanos da criança e do adolescente (NUNES, 2014, p. 69).

Para que o sistema possa funcionar, é necessária uma rede de organização de pessoas e instituições que buscam cooperar entre si, permitindo uma troca de informações e apoio, potencializando os efeitos do atendimento à criança e ao adolescente, dividida em rede primaria de apoio e rede protetiva (NUNES, 2014, p. 71).

A rede primária de apoio é formada por pessoas próximas: família, amigos, vizinhos, colegas de trabalho. Quando se fala em envolver a comunidade em uma prática restaurativa, considera-se aproximar essa rede primária para que atue em parceria, auxiliando como facilitadores e suporte em casos de vitimização, potencializando referências àquele adolescente e fortalecendo vínculos. Já a rede protetiva abarca os órgãos - governamentais ou não - encarregados de zelar pelos direitos da criança e do adolescente. São exemplos de órgãos da rede: Sistema Único de Assistência Social (SUAS) - que abrange os Centros de Referência de Assistência Social (CRAS) e Centros de Referência Especializada de Assistência Social (CREAS) - Unidades Básicas de Saúde (UBS), Centros de Atenção Psicossocial (CAPS) - que pode ser subdivido em adulto, infantil e álcool e drogas - Conselho Tutelar, Escola, Ministério Público, Varas de Infância e Juventude e Serviços Auxiliares da Infância e Juventude (SAIJ) (NUNES, 2014, p. 71-78).

Por esses motivos, a escola deve se amparar na rede primária e participar efetivamente da rede de proteção, assim como cada parte integrante das redes deve trabalhar em conjunto visando a promoção das garantias das crianças e adolescentes já previstas em lei.

Em razão de sua abordagem voluntária, a promoção de círculos restaurativos no ambiente escolar pode ser encarada como uma alternativa para despertar no adolescente o senso de responsabilidade e interesse em permanecer na escolar por vontade própria e visando perspectivas futuras. Permite ao adolescente entender que o caminho da educação é mais benéfico a ele do que o da criminalidade, assim como forma adultos que sabem e optam pela resolução de conflitos visando a promoção da Cultura da Paz.

Destarte, a aplicação da Justiça Restaurativa no ambiente escolar, pressupõe a sua participação individual como sujeito de direitos, atendido pela sociedade (representada por sua escola), família e comunidade no geral, sendo garantido sua igualdade, a partir do acolhimento ao diálogo, valorizando suas diferenças, sem se descuidar da sua responsabilização no próprio ambiente e possibilitando um recomeço com novos projetos. 


\section{Considerações Finais}

Com base no estudo realizado no presente trabalho vislumbra-se que a escola tem potencial para ser uma grande incentivadora no atendimento de adolescentes. Entretanto, não há de se olvidar que essa responsabilidade é coletiva.

Conclui-se com a presente pesquisa que por meio da Justiça Restaurativa a escola pode educar e reeducar o adolescente para ser sujeito de direitos, mostrando-lhe conceitos de limites e responsabilidade, promovendo o despertar sobre a restauração de danos e sobre o respeito com a vida do outro. Além disso, toda a sociedade pode, a parir da Justiça Restaurativa, buscar caminhos de perdão e menos vingança com ações conjuntas que gerem menos punição e isolamento, gerando responsabilidades, dando voz aos verdadeiros interessados na resolução, evitando que seus conflitos sejam resolvidos por terceiros - que em alguns casos, sequer conhecem a realidade daquele ambiente -, e permitindo o envolvimento de toda a comunidade escolar e familiar em casos que podem ser resolvidos sem a tomada de medidas judiciais, despertando no aluno o interesse em permanecer nesse ambiente escolar e evitando que seja acolhido pela criminalidade.

O trabalho deve ser focado na formação de professores e profissionais do ambiente escolar, visando instigar nos pais e na comunidade o interesse em participar das práticas restaurativas e a formação de facilitadores nesse ambiente, demonstrando que, a longo prazo, esses benefícios retornam para a própria comunidade. Considerando que a participação dos envolvidos é voluntária, a divulgação do projeto e como ele funciona faz-se mister para seu sucesso.

Ademais, caminhos já estão sendo traçados para efetivação da Justiça Restaurativa no ambiente escolar dentro do Município de Guarapuava/Paraná, como é o exemplo do "Projeto Restaurar", incentivado pelo Centro Universitário Campo Real, que promove círculos restaurativos para alunos nas escolas da região.

Por fim, resta evidente a necessidade de um posicionamento estatal eficaz por meio de políticas públicas a favor da promoção da Justiça Restaurativa, bem como o aprimoramento da boa conexão entre família, escola e comunidade com o fortalecimento com a Rede de Proteção. Outrossim, a participação dos Conselhos Tutelares e a promoção da capacitação de facilitadores (funcionários da escola e comunidade) são fundamentais para realização de práticas restaurativas no ambiente escolar, visando soluções para resolução de conflitos a partir da comunicação não violenta que pressupõe a construção da Cultura da Paz.

\section{Referências}

BRANCHER, Leoberto (coord). A paz que nasce de uma nova justiça - Paz Restaurativa: um ano de implantação da justiça restaurativa como política de pacificação social em Caxias do Sul. Caxias do Sul: Núcleo de Justiça Restaurativa, 2013.

BRASIL. Lei no 8.069 de 13 de Julho de 1990. Disponível em: <http://www.planalto.gov.br/ccivil_03/ LEIS/L8069.htm > Acesso em: 08 set. 2018.

CARVALHO, Luiza Maria S. dos Santos. Notas sobre a promoção da equidade no acesso e intervenção da Justiça Brasileira. In: SLAKMON, Catherine; VITTO, Renato Campos de; PINTO, Renato Sócrates Gomes (Org) Justiça Restaurativa. v. 1. Florianópolis:[s.n.], p. 211, 2005.

DIAS, Aline Fávaro. Entre sociabilidade e movimentos de resistência: o significado da educação escolar para jovens autores de ato infracional. Revista Eletrônica de Educação, São Carlos. v. 7, n. 1, mai. 2013. 
FROESTAD, Jan; SHEARING, Clifford. Prática da Justiça - O Modelo Zwelethemba de Resolução de Conflitos. In: SLAKMON, Catherine; VITTO, Renato Campos de; PINTO, Renato Sócrates Gomes (Org) Justiça Restaurativa. v. 1. Florianópolis:[s.n.], p. 79, 2005.

GIL, Antonio Carlos. Como elaborar Projetos de Pesquisas. 4.ed. São Paulo: atlas, 2002.

MELHEM, Patricia Manente; ROSAS, Rudy Heitor. Justiça Restaurativa: Principais conceitos e o objetivo de desenvolvimento sustentável n. 16. 2015, Belo Horizonte. Anais XXIV Congresso Nacional do CONPEDI. Belo Horizonte, 2015.

MELO, Eduardo Rezende. Justiça restaurativa e seus desafios histórico-culturais - Um ensaio crítico sobre os fundamentos ético-filosóficos da justiça restaurativa em contraposição à justiça retributiva. In: SLAKMON, Catherine; VITTO, Renato Campos de; PINTO, Renato Sócrates Gomes (Org) Justiça Restaurativa. v. 1. Florianópolis:[s.n.], p. 53, 2005.

MARSHALL, Chris; BOYACK, Jim; BOWEN, Helen. Como a Justiça Restaurativa assegura a boa prática Uma Abordagem Baseada em Valores. In: SLAKMON, Catherine; VITTO, Renato Campos de; PINTO, Renato Sócrates Gomes (Org) Justiça Restaurativa. v. 1. Florianópolis:[s.n.], p. 267, 2005.

MORRIS, Alisson - Criticando os críticos. Uma breve resposta aos críticos da Justiça Restaurativa. In SLAKMON, Catherine.; VITTO, Renato Campos Pinto de; PINTO, Renato Sócrates Gomes (Org) Justiça Restaurativa. v.1. Florianópolis: [s.n.], p. 439, 2005.

MUMME, Monica. Justiça Restaurativa: um caminho de valor social que acontece no coletivo. In PELIZZOLI, Marcelo L. (Org) Justiça Restaurativa: caminhos da pacificação social. 1. ed. Rio Grande do Sul: EDUCS, p. 87, 2016.

NUNES, Antonio Carlos Ozório (coord). Diálogos e Mediação de Conflitos nas Escolas: Guia prático para Educadores. Brasília: Gráfica e Editora Movimento, 2014.

PENIDO, Egberto de Almeida - Cultura de Paz e Justiça Restaurativa: uma jornada de alma. In PELIZZOLI, Marcelo L. (Org) Justiça Restaurativa: caminhos da pacificação social. 1. ed. Rio Grande do Sul: EDUCS, p. 69, 2016.

PINTO, Renato Sócrates Gomes. Justiça Restaurativa é Possível no Brasil?. In: SLAKMON, Catherine; VITTO, Renato Campos de; PINTO, Renato Sócrates Gomes (Org) Justiça Restaurativa. v. 1. Florianópolis:[s.n.], p. 19, 2005.

PRANIS, Kay. Processos Circulares. Traduzido por Tônia Van Acker. 1 ed. São Paulo: Palas Athena Editora, 2010.

SALLES, Vírginia Ostroski; SALLES, Nei Alberto. Redimencionar o conceito de conflito para qualificar a prática da educação para a paz na escola: uma discussão pertinente. Ponta Grossa, 2016. Disponível em: encurtador.com.br/mqvFM. Acesso em: 12 out. 2017.

SANTOS, Mayta Lobo dos; GOMIDE, Paula Inez Cunha. JUSTIÇA RESTAURATIVA NA ESCOLA: Aplicação e Avaliação do Programa. 1 ed. Curitiba: Juruá, 2014.

ZEHR, Howard. Justiça Restaurativa. Traduzido por Tônia Van Acker. 2 ed. São Paulo: Palas Athena Editora, 2015. 